\title{
Prevelence of Hepatits B in Catchment Area of Khairpur Medical College Hospital Khairpure Mirs Pakistan
}

\author{
Badvi JA ${ }^{*}$, Jawed $\mathbf{M}^{2}$ and Jawed $\mathbf{K}^{3}$ \\ 1Professor and head of Pathology Department, Khairpure Medical College Khairpur \\ Mirs, Pakistan \\ ${ }^{2}$ Post graduate Researcher Liaquat University of health sciences Jamshoro, Pakistan \\ ${ }^{3}$ Senior Dow International Medical College Karachi, Pakistan
}

\section{Research Article \\ Volume 3 Issue 1}

Received Date: December 18, 2017

Published Date: February 05, 2018

*Corresponding author: Jawed Ahmed Badvi, Professor and head of Pathology Department, Khairpure Medical College, Khairpure Mirs, Pakistan, E-mail: jawedbadvi1958@gmail.com

\section{Abstract}

Hepatitis B is prevalent in khairpure Mirus, Pakistan, yet up-to-date data on the epidemiology of hepatitis B in Khairpure Mir's catchment area of Teaching hospital, KMC, khairpur, data is not available before in this catchment area.

Methodology: One thousand, three hundred and ninety seven patients were referred to pathological laboratory of kmc teaching hospital khairpur Pakistan, who were suspected for hepatitis HBV, from different OPDs, and data was collected from January 2017 to august 2017 from which Eight hundred ninety eight were positive on Elisa method, were screened for HBV. Patients of either sex, with more than thirty years of age were included. From which 898 HBV were positive on Elisa method.

Result: Data was collected from January 2017 to August 2017 from which were Eight hundred ninety eight were positive on Elisa method, were screened for HBV and HCV. Patients of either sex, with more than thirty years of age were included. From which 898 HBV were positive on Elisa method OUT OF thirteen hundred and ninety seven advised for hepatitis B. Means $64 \%$ is very high prevalence.

Conclusion: Data suggest a moderate to high prevalence of HBV, at KMC Hospital catchment area Khairpure Mirs, Pakistan. The modes of transmission of hepatitis B in Pakistan implicate contaminated needle used in medical care, drug abuse, unsafe blood and blood product transfusion, and blood bank running in the town without qualified pathologists, as the major causing factors.

Keywords: Hepatitis B; KMC; Khairpur Mirs; Prevelence; Data

\section{Introduction}

Hepatitis B virus (HBV) is among the principal causes of severe liver disease, including hepatocellular carcinoma and cirrhosis-related end-stage liver disease. The World Health Organization (WHO) estimates that there are 350 million people with chronic HBV infection and 170 million people with chronic HCV infection 


\section{Vaccines \& Vaccination Open Access}

worldwide [1,2]. Hepatitis $B$ is estimated to result in $5,63,000$ deaths annually [3]. Given its large population (165 million) and intermediate to high rates of infection, Pakistan is among the worst afflicted nations [1,2].

Hepatitis B virus (HBV) infection is a major global health problem, especially in Asia, Africa, southern Europe and Latin America [1-4]. About 2 billion people are infected with HBV worldwide, and 400 million among them are suffering from chronic HBV infection [2,4-6]. Pakistan is highly endemic with HBV with nine million people infected with $\mathrm{HBV}$ and its infection rate is on a steady rise [7-9]. The reason may be the lack of proper health facilities, poor economical status and less public awareness about the transmission of major communicable diseases including HBV, HCV and HIV [6].

The clinical course and sequel of chronic hepatitis vary among individuals. Infection with HBV leads to a wide spectrum of clinical presentations, ranging from asymptomatic carrier state to acute self-limiting infection or fulminant hepatic failure, chronic hepatitis with progression to cirrhosis, and hepatocellular carcinoma (HCC) [2].

Studies are too limited to give a clear picture of the prevalence of HBV at the National level, especially among otherwise healthy individuals. Most previous studies targeted different small groups of individuals with some clinical indications therefore; these do not accurately reflect the overall prevalence in Pakistan [7,8]. The present article briefly presents the prevalence, risk factors associated with HBV transmission, awareness status and HBV genotypes prevalent in Pakistani population. Prevalence of HBV in Pakistan, HBV in Blood donors, Hepatitis B virus in general population, HBV in Pakistani healthcare workers, HBV in surgical patients, HBV infection in women and children, HBV infection in prisoners, $\mathrm{HBV}$ in diseased population in Pakistan, $\mathrm{HBV}$ in injection drug users, epidemiology of HBV in Pakistan, HBV genotypes in Pakistan and awareness about HBV in Pakistani population. Two hundred and twenty nine different studies (articles/repots) were obtained from the literature search, out of which 106 published from 1998 to 2010 were included in the present review. Studies full filling the following criteria were included:

a) Samples were collected from Pakistani individuals.

b) An obvious description of the methods of detection of HBV infection and genotyping.

c) Information about the number of individuals studied and their residing area were reported.

d) Studies reporting risk factors and awareness status in Pakistani population were included to discuss the HBV prevalence in different population groups.
Four different studies showed $7.397 \% \pm 2.012 \% \mathrm{HBV}$ prevalence rates in patients undergoing surgery [10,11]. The lack of routine serological screening in Pakistani hospitals prior to surgery is one of the factors responsible for increased disease transmission [12]. It is recommended that every case undergoing surgery should be screened for hepatitis B and C virus infections [13].

Major risk factors for mother to infant transmission include increasing maternal age, number of pregnancies, repeated injections and addiction [14]; major risk factors in surgical patients include re-use of contaminated syringes, contaminated surgical instruments and blood products [12]; risk factors in pregnant women (antenatal) include ear and nose prick, history of jaundice among them or with their partner [15], history of blood transfusions, history of injections $[16,15]$, tooth extraction [16]; in prisoners significant risk factors were intravenous drug abuse $[17,18]$. rural origin and shaved by barber [18]; Major risk factors for health care workers are dental procedures, needle prick and surgical procedures [19]; most important risk factors for HBV infection in young recruits were sharing of razors, history of intravenous injections, jaundice in the subject and jaundice in family [20]; in children key risk factors were injection in the past, surgical and dental procedures, blood transfusion, accidental cuts at barber shops and umbilical cord cut through unsterilized instruments at home in thalassaemic children there is a definite risk factor of repeated blood transfusion, while main risk factors among the obstetrical and gynecological population were unsafe surgery, injections and inadequately screened blood transfusions [21-23]. Relatively low prevalence in the female prostitutes (high risk group) reflects the effect of legal, social and religious constraints in Pakistani society Most of these factors are easily preventable and need awareness in general population and the healthcare workers [24].

\section{Awareness about HBV in Pakistani population}

Nasim, et al. [25] conducted a questioner bases survey in Karachi to assess knowledge about viral hepatitis among college girls and showed that $57 \%$ of them do not have information about transmission of hepatitis B virus. In another survey at obstetric and gynecology clinic at Hyderabad showed that most of the women $(67.76 \%)$ know that $\mathrm{HBV}$ is a viral disease, $75.20 \%$ responded that it affect liver, $33.88 \%$ believed that it could be transmitted by infected blood transfusion, $17.35 \%$ believed that it could be transmitted from mother to child, $19.0 \%$ mentioned sexual intercourse responsible for $\mathrm{HBV}$ infection, while $40.49 \%$ and $38.0 \%$ mentioned 


\section{Vaccines \& Vaccination Open Access}

contaminated needles and un-sterilized instruments as a source of HBV infection, respectively [26]. Mengal, et al. [27] surveyed nursing students at nursing school, Bolan medical complex hospital, Quetta and reported that only $37.2 \%$ of them were completely vaccinated and $25.0 \%$ had not been vaccinated for HBV. Chaudhry, et al. [28] reported that $97.4 \%$ of the barbers at Islamabad use new blade for every customer but only 38\% of them have knowledge about routes of infection of HBV and HCV. In another study, Waheed, et al. [29].

\section{Methodology}

\section{Study Area}

This descriptive hospital based study was conducted between January, 2017 to August, 2017 at Kahirpure medical college teaching hospital from pathological laboratory catchment Area. This hospital is a 500 bed Medical college based hospital khairpure Mirs Pakistan. That offers both emergency care and specialized care for patients of all ages. The pathological research laboratory is situated in the hospital premises.

\section{Patient's Assessment}

After getting verbal consent from all eligible subjects, pre-test counseling was done with the assurance that all information obtained would be kept confidential and for the purpose of research only.

\section{Inclusion Criteria}

All Patients above thirty years, with either sex, having no documented past history of chronic liver disease, HBV were included, Patients requiring urgent surgical intervention were included from screening.

The subjects were interviewed on a structured questionnaire regarding age, sex, place of residence, literacy level, exposure to blood transfusions, visit to barber shops, any history of surgery, family history etc.

\section{Screening for $\mathrm{HBV}$}

A two to three-milliliter blood sample was collected by venepuncture aseptically into a sterile test tube from each patient and tested for HBsAg antibodies within first one hours of collection. The screening was performed through ELISA METHOD detection of surface antigen of hepatitis-B virus.

\section{Result}

This result showing from KMC teaching hospital khairpure Mir's catchment area the trend of positive HBV, irrelative of gender, table 1 shows the prevalence of HBV in summer season, which is to be probe why in summer season and to be further investigated and needs research on this issue. Total attended 1397 patients for investigation for $\mathrm{HBV}$, and 898 were positive that becomes $64.2 \%$ is the highest rate of prevalence rate of HBV in KMC Khairpure Pakistan, teaching hospital catchment which is highest prevalence rate in this area, suggesting uncontrolled disease in this area, proving no effective vaccination even going on in this area, which is again is to be investigated.

\begin{tabular}{|c|c|c|}
\hline Months 2017 & HBV Eliza Total & Positive Cases \\
\hline JAN & 124 & 82 \\
\hline FEB & 190 & 90 \\
\hline MARCH & 196 & 90 \\
\hline APRIL & 188 & 109 \\
\hline MAY & 202 & 132 \\
\hline JUNE & 188 & 137 \\
\hline JULY & 140 & 114 \\
\hline AUG & 169 & 144 \\
\hline
\end{tabular}

Table 1: The prevalence of HBV in summer season

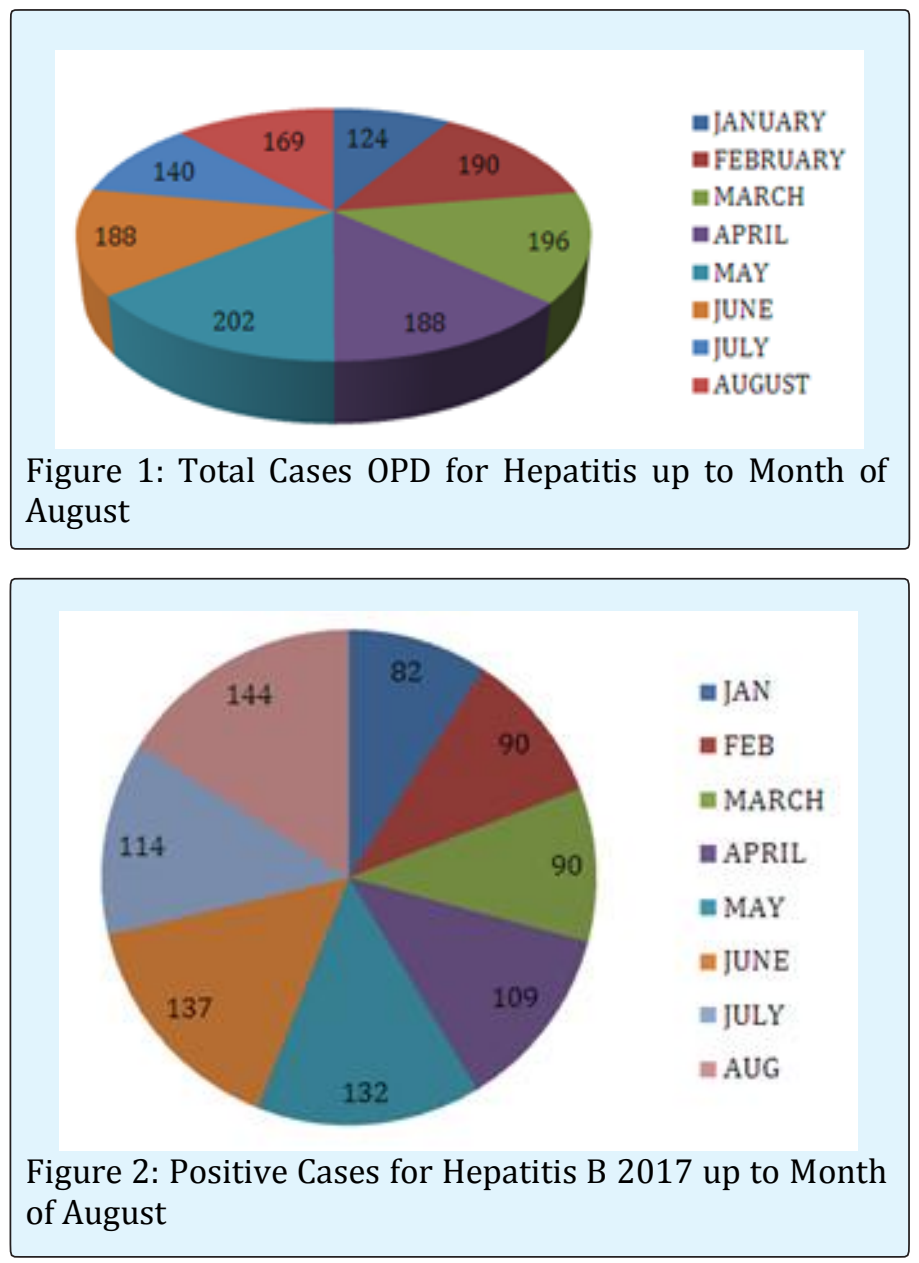




\section{Vaccines \& Vaccination Open Access}

\section{Discussion}

Significant lack of knowledge and poor attitude towards HBV and HCV in surgical patients at Nawabshah area. We suggest aggressive public awareness programs especially in rural areas and people at high risk to decrease the burden of HBV infection in Pakistan. The burden of HBV and HCV disease is increasing globally and Pakistan is no exception. Sindh province, which is one of four provinces in Pakistan, has a population of $30,439,893$. The rural proportion of Sindh province (interior Sindh) is $74 \%$ of total population of Sindh. Hyderabad is the second largest city after Karachi, in Sindh and fifth largest in Pakistan.

\section{References}

1. Li G, Li W, Guo F, Xuc S, Zhaod N, et al. (2010) A novel real-time PCR assay for determination of viral loads in person infected with hepatitis B virus. J Virol Methods 165(1): 9-14.

2. Paraskevis D, Haida C, Tassopoulos N, Raptopoulou M, Tsantoulas D, et al. (2002) Development and assessment of a novel real-time PCR assay for quantitation of HBV DNA. J Virol Methods 103(2): 201-212.

3. Alam MM, Zaidi SZ, Malik SA, Naeem A, Shaukat S, et al. (2007) Serology based disease status of Pakistani population infected with Hepatitis B virus. BMC Infect Dis 7: 64 .

4. Noorali S, Hakim ST, McLean D, Kazmi SU, Bagasra O (2008) Prevalence of Hepatitis B virus genotype D in females in Karachi, Pakistan. J Infect Dev Ctries 2(5): 373-378.

5. Hakim ST, Kazmi SU, Bagasra O (2008) Seroprevalence of Hepatitis B and C Genotypes Among Young Apparently Healthy Females of Karachi-Pakistan. Libyan J Med 3(2): 66-70.

6. Khan MA, Ali AS, Ul Hassan Z, Mir F, Ul Haque S (1998) Seroprevalence of hepatitis B in children. Pak Pediatr J 22(2): 75-77.

7. Idrees M, khan S, Riazuddin S (2004) Common genotypes of hepatitis B virus. J Coll Physicians Surg Pak 14(6): 344-347.

8. Zhu R, Zhang H, Yu H, Li H, Ling YQ, et al. (2008) Hepatitis B virus mutations associated with in situ expression of hepatitis B core antigen, viral load and prognosis in chronic hepatitis B patients. Pathol Res Pract 204(10): 731-742.

9. Hepatitis prevention \& control program Sindh (chief minister's initiative) 2009. directorate general health services, Hyderabad, Sindh, Pakistan

10. Moosa FA, Shaikh BA, Choudhry MS, Zuberi BF, Khan FW, et al. (2009) Frequency of hepatitis B and C in pre-operative patients for elective surgery. JLUMHS 8(2): 150-152.

11. Shirazi B, Jaffery AH, Kishwar M, Shamim MS. Screening for hepatitis B \& C in surgical patients. J Coll Phy Sur Pak. 2004; 9:10-3.

12. Masood Z, Jawaid M, Khan RA, Rehman S (2005) Screening for hepatitis B \& C: A routine preoperative investigation. Pak J Med Sci 21(4): 455-459.

13. Chaudhary IA, Khan SA, Samiullah (2005) Should we do hepatitis $B$ and $C$ screening on each patient before surgery: Analysis of 142 cases. Pak J Med Sci 21(3): 278-280.

14. Mehnaz A, Batool A, Bano KA, Khan MI, Hussain R (2008) Antenatal screening of women for hepatitis B and $C$ in an out-patient department. J Dow Uni Health Sci 2(1): 32-35.

15. Yousfani S, Mumtaz F, Memon A, Memon MA, Sikandar R (2006) Antenatal screening for hepatitis B and $\mathrm{C}$ virus carrier state at a university hospital. JLUMHS 5(1): 24-27.

16. Mehnaz A, Hashmi H, Syed S, Kulsoom (2002) Hepatitis B markers in mothers and its transmission in newborn. J Coll Phy Sur Pak 12(4): 240-242.

17. Ali N, Khattak J, Anwar M, Tariq WZ, Nadeem M, et al. (2002) Prevalence of hepatitis B surface antigen and hepatitis $\mathrm{C}$ antibodies in young healthy adults. Pak J Pathol 13(4): 3-6.

18. Kazi AM, Shah SA, Jenkins CA, Shepherd BE, Vermund SH (2010) Risk factors and prevalence of tuberculosis, human immunodeficiency virus, syphilis, hepatitis $B$ virus, and hepatitis $C$ virus among prisoners in Pakistan. Int J Infect Dis 14(S3): e60-e66.

19. Sarwar J, Gul N, Idris M, Rehman A, Farid J, Adeel MY (2008) Seroprevalence of hepatitis B and hepatitis C in healthcare workers in Abbottabad. J Ayub Med Coll Abottabad 20(3): 27-29. 


\section{Vaccines \& Vaccination Open Access}

20. Hussain AB, Hashim R, Rehman K (2005) Hepatitis B surface antigen. Prof Med J 12(3): 213-217.

21. Khan A, Aqeel M, Tariq SM, Khattak AA (2009) Frequency of hepatitis B surface antigen and its association with possible risk factors in hospitalized pediatric patients. Pak Paed J 33(1): 39-43.

22. Burki MFK, Hassan M, Ali L, Wadood MZ (2009) Frequency of hepatitis B virus in regularly blood transfused beta thalassemia major patients. Pak Paed J 33(3): 153-156.

23. Sami S, Korejo R, Bhutta SZ (2009) Prevalence of hepatitis B and C: A Jinnah postgraduate medical centre experience. J Obstetrics and Gynecology Res 35(3): 533-538.

24. Anwar MS, Jaffery G, Rasheed A (1998) Serological screening of female prostitutes for anti-HIV and hepatitis B surface antigen. Pak J Health 35(3-4):6973.
25. Nasim S, Shahid A, Pirzada AG, Memon AA (2009) Perception of adolescent females about viral hepatitis in urban and rural Sindh. Pak J Med Res 48(3):71-73.

26. Haider G, Haider A (2008) Awareness of women regarding hepatitis B. J Ayub Med Coll Abbottabad 20: 141-144.

27. Mengal H, Howteerakul N, Suwannapong N, Rajatanun T (2008) Factors relating to acceptance of hepatitis B virus vaccination by nursing students in a tertiary hospital, Pakistan. J Health Popul Nutr 26: 4653.

28. Chaudhry MA, Rizvi F, Ashraf MZ, Afzal M, Niazi S (2010) Knowledge and practices of barbers regarding hepatitis B and hepatitis C in Bahra Kahu, IslamabadPakistan. Rawal Med J 35(1): 37-40.

29. Waheed Y, Saeed U, Safi SZ, Chaudhry WN, Qadri I (2010) Awareness and risk factors associated with barbers in transmission of hepatitis $\mathrm{B}$ and $\mathrm{C}$ from Pakistani population: barber's role in viral transmission. Asian Biomedicine 4(3): 435-442. 